\title{
Dinâmica populacional do ácaro-do-bronzeado na cultura da erva-mate em Chapecó, Santa Catarina
}

\author{
Population dynamic of tan-mite in mate-tea in Chapecó, Santa Catarina
}

\author{
João Vieira Neto ${ }^{\mathrm{I}}$ Alessandro Dal'Col Lúcio ${ }^{\mathrm{II}}$ Lindolfo Storck $^{\text {II }}$ \\ Luis Antônio Chiaradia ${ }^{\text {III }}$ Sidinei José Lopes ${ }^{\text {II }}$
}

\section{RESUMO}

\begin{abstract}
Este trabalho teve como objetivos identificar a localização mais provável do ácaro-do-bronzeado (Dichopelmus notus Keifer) na planta de erva-mate e estudar a influência dos fatores climáticos em sua flutuação populacional. O estudo foi conduzido no município de Chapecó, SC, em um erval de dez anos, com árvores espaçadas no arranjo de 2,5 X 4,0m. Em três áreas de aproximadamente $2.500 \mathrm{~m}^{2}$, foram selecionadas 30 plantas, sendo avaliada a infestação quinzenal no período de 27/01/2004 a 10/01/2005. Foram observadas 18 folhas maduras de dez plantas escolhidas ao acaso em cada área, sendo seis no terço superior, seis no terço médio e seis no terço inferior, três em cada localização da copa, externa e interna. As inspeções foram executadas diretamente nos ervais utilizando lentes com aumento de dez vezes e $1 \mathrm{~cm}^{2}$ de campo fixo. Os resultados evidenciaram que os ácaros concentram-se na parte externa da copa da planta, nos terços superior e médio. As maiores infestações de $\boldsymbol{D}$. notus ocorrem nos meses de fevereiro a abril, não tendo sido encontrada correlação linear significativa entre os elementos climáticos e o número médio de ácaro por $\mathrm{cm}^{2}$ de folha.
\end{abstract}

Palavras-chave: amostragem de ácaro, Ilex paraguariensis, Dichopelmus notus.

\section{ABSTRACT}

This study was was aimed at identifing the most likely location of the tan-mite (Dichopelmus notus Keifer) in mate-tea orchards and to study the influence of climate factors in its population fluctuation. The study was carried out in orchard of ten years, in the arrangement of $2.5 \times 4.0 \mathrm{~m}$ with height of $1.5 \mathrm{~m}$, located in Chapecó, Santa Catarina state, Brazil. In three areas of approximately $2,500 \mathrm{~m}^{2}$, distant between itself

\begin{abstract}
about 100m, 30 plants had been selected randomly. Fortnightly, in the period of 27/01/2004 to 10/01/2005, were evaluated infestation of $\boldsymbol{D}$. notus in 18 mature leaves of ten plants in each area, being six in the upper one-third, six in the medium onethird and six in lower one-third, three in each location of the crown, external and internal. The evaluations were executed directly in the orchard, using lenses with increase of ten times and $1 \mathrm{~cm}^{2}$ of fixed field. The results had evidenced that: the mites concentrate themselves in the external part of the plant in the upper one-third part of canopy as well as in the medium part one-third. The greatest infestation of $\boldsymbol{D}$. notus occurred between February and April, not having been found significant correlation between the climate elements and the average number of mite for $\mathrm{cm}^{2}$ of leaf.
\end{abstract}

Key words: mite sampling, Ilex paraguariensis, Dichopelmus notus.

\section{INTRODUÇÃO}

A erva-mate (Ilex paraguariensis A. St.-Hil: Aquifoliaceae) é uma essência florestal que ocorre naturalmente nas regiões temperadas e subtropicais da América do Sul, entre os paralelos $21^{\circ}$ e $30^{\circ}$ de latitude Sul, e meridianos $48^{\circ}$ e $56^{\circ}$ de longitude Oeste, principalmente em altitudes que variam entre 500 a 1000 m(DA CROCE \& FLOSS, 1999).

A produção de erva-mate do Brasil, segundo produtor mundial, em 2004 foi de 403,3 mil toneladas de folha verde, gerando R\$118 milhões em divisas.

'Centro Tecnológico, Universidade Comunitária Regional de Chapecó (Unochapecó), C.P. 747, 89809-000, Chapecó, SC, Brasil.

E-mail: jvn@unochapeco.edu.br.

"Departamento de Fitotecnia, Centro de Ciências Rurais (CCR), Universidade Federal de Santa Maria (UFSM), 97105-900, Santa

Maria, RS, Brasil. E-mail: adlucio@smail.ufsm.br. Autor para correspondência.

IIIEmpresa de Pesquisa Agropecuária e Extensão Rural de Santa Catarina S A, Gerência Administrativa de Chapecó, Centro de Pesquisa Para Agricultura Familiar. 
Destacaram-se como produtores os estados do Rio Grande do Sul (55,3\%), Paraná (33,1\%), Santa Catarina (9,3\%) e Mato Grosso do Sul (2,3\%) (ANUÁRIO BRASILEIRODAERVA-MATE, 2000; IBGE, 2006). No Estado de Santa Catarina, a erva-mate está presente em aproximadamente 19 mil propriedades rurais de 120 municípios e envolve direta ou indiretamente cerca de 69 mil trabalhadores. Além da importância como fonte de renda, principalmente para a agricultura familiar, a erva-mate representa uma manifestação cultural que identifica os habitantes dos Estados da região Sul do Brasil. Herança herdada dos índios Guaranis que habitavam essa região na época da colonização, o hábito de tomar o chá, feito a partir das folhas da erveira - chamado de chimarrão -, permanece até hoje, constituindo-se, inclusive, em um dos símbolos oficiais do Rio Grande do Sul (LAVOURA PECUÁRIA, 1978; DACROCE, 2000; PASINATO, 2003).

Durante muitos anos, a exploração da ervamate se restringia a ervais nativos, mas recentemente passou a ser cultivada também em monocultura, sistema que favorece o desenvolvimento de pragas (PENTEADO, 1995). Em monocultivos, o ácaro-dobronzeado (Dichopelmus notus Keifer: Eriophyidae), específico dessa cultura, que em ervais nativos, encontrava-se em baixos níveis populacionais, provoca maiores danos, com elevados prejuízos aos produtores dos Estados do Sul do Brasil (SANTANA et al.,2000). $\mathrm{O}$ ataque desse ácaro leva a uma paralisação do crescimento e à morte de folhas novas; nas folhas velhas, provoca o bronzeamento e queda prematura (CHIARADIA, 2001a). DE COLL \& CACERES (1995) consideram o ácaro-do-bronzeado uma das principais pragas da cultura da erva-mate na Argentina, principalmente nos ervais das províncias de Missiones e Corrientes.

A menor produção dos ervais infestados pelo ácaro-do-bronzeado e a redução da qualidade da matéria-prima, em determinados períodos do ano, justificam a realização de estudos capazes de esclarecer aspectos da bioecologia dessa espécie, visando a aprimorar o seu manejo e reduzir seus danos. Desta forma, o acompanhamento dos níveis de infestação de D. notus é importante para a adoção de práticas racionais visando a seu manejo integrado. Esse procedimento requer a definição de metodologias de amostragem que permitam estimar com eficiência e rapidez sua densidade populacional (CHIARADIA, 2001a).

Este trabalho teve como objetivos identificar a localização mais provável do ácaro $\boldsymbol{D}$. notus na planta e estudar a influência dos fatores climáticos em sua flutuação populacional, nas condições do município de Chapecó, Santa Catarina.

\section{MATERIAL E MÉTODOS}

O estudo foi conduzido em um erval de dez anos, de propriedade da empresa Ouro Verde, cujas árvores estavam espaçadas no arranjo de 2,5m entre linhas e 4,0m entre plantas e tinham altura de poda da planta de $1,5 \mathrm{~m}$. Trata-se de um plantio comercial de erva-mate solteira a pleno sol, onde as colheitas são realizadas anualmente no sistema manual. Durante os estudos, as plantas não foram submetidas a tratamentos com produtos fitossanitários e a roçada mecânica foi adotada para o controle de ervas daninhas.

A área localiza-se no distrito de Marechal Bormann, município de Chapecó-SC, com coordenadas geográficas: $27^{\circ} 05^{\prime}$ de latitude Sul e 5256’ de longitude Oeste, a uma altitude média de 550m. Segundo a classificação climática de Köppen, a região apresenta um clima mesotérmico úmido com verão quente (Cfa) (SANTA CATARINA, 1994).

Em três áreas de aproximadamente $2.500 \mathrm{~m}^{2}$, distantes entre si cerca de $100 \mathrm{~m}$, foram amostradas 10 plantas em cada área. As plantas foram selecionadas ao acaso, entre aquelas que apresentavam boa formação de copa. Devido à realização da poda comercial, durante os meses de maio a setembro, trabalhou-se com talhões móveis, para que fosse possível a obtenção de plantas com copa cheia durante o ano todo. Quinzenalmente, no período de 27/01/2004 a 10/01/2005, foi avaliada a infestação de $\boldsymbol{D}$. notus em 18 folhas maduras, sendo seis no terço superior, seis no terço médio e seis no terço inferior, em cada terço, três na parte externa da copa e três na interna. Ao total, foram observadas 540 folhas em cada data de amostragem. As avaliações foram executadas diretamente nos ervais, utilizando lupa com aumento de dez vezes e $1 \mathrm{~cm}^{2}$ de campo fixo. Na parte superior de cada folha, foi realizada uma única contagem do número de ácaros, na área previamente delimitada pelo campo fixo da lupa, conforme metodologia preconizada por OLIVEIRA et al.(1982).

A diferenciação entre as duas espécies de eriofídeos que ocorrem nos ervais (D. notus e Disella ilicicola Navia \& Flechtmann) foi baseada na variação do tamanho e da coloração destes ácaros. Além dessas características, levou-se em consideração o local preferencial de infestação de cada espécie. Enquanto D. ilicicola infesta preferencialmente a face inferior (abaxial) das folhas mais velhas, D. notus prefere, principalmente, as brotações e a face superior (adaxial) de folhas novas (FERLA et al.,2005; NAVIA \& FLECHTMANN, 2005; CHIARADIA et al., 2006).

Adotou-se o modelo de análise conjunta de experimento bifatorial (Terço x profundidade) no 
delineamento blocos ao acaso, com amostragem na parcela.

A análise foi efetuada considerando doze meses, três terços, duas profundidades e 30 repetições (plantas), tendo sido efetuadas três amostras em cada combinação de altura de terço e profundidade de copa. $\mathrm{O}$ número de ácaros por $\mathrm{cm}^{2}$ folha foi transformado para $(x+0,5)^{1 / 2}$, com a finalidade de proporcionar a normalidade dos erros.

As análises de variância foram feitas através do programa NTIA (EMBRAPA, 1997) e as médias comparadas pelo teste de Tukey, em nível de 5\% de probabilidade de erro.

Os fatores climáticos utilizados para o estudo foram obtidos na Estação Agrometeorológica do Centro de Pesquisas para Agricultura Familiar da Empresa de Pesquisa Agropecuária e Extensão Rural de Santa Catarina (CEPAF /Epagri-Chapecó), consideradas as observações diárias das temperaturas mínima e máxima $\left({ }^{\circ} \mathrm{C}\right)$, da precipitação pluviométrica $(\mathrm{mm})$, da umidade relativa do ar (\%) e da velocidade do vento $\left(\mathrm{m} \mathrm{s}^{-1}\right)$, no período de janeiro de 2004 a janeiro de 2005.

O coeficiente de correlação linear simples foi utilizado para quantificar as relações entre o número médio de $\boldsymbol{D}$. notus por $\mathrm{cm}^{2}$ de folha, observados em cada data de amostragem nos diferentes locais das plantas de erva-mate, e as variáveis climáticas. Para efeito de cálculo, foram obtidas as médias das temperaturas mínima e máxima, a soma da precipitação pluviométrica, a média da umidade relativa e a média da velocidade do vento, a partir das observações diárias entre os intervalos de amostragem, sendo que, para a primeira amostra, foram tomados os quinze dias anteriores.
A significância da correlação linear foi verificada pelo teste t de Student, em nível de 5\% de probabilidade de erro, com n-2 graus de liberdade.

\section{RESULTADOS E DISCUSSÃO}

O resultado da análise de variância está apresentado na tabela 1 , especificando-se as fontes de variação, os graus de liberdade, os quadrados médios e o teste F. O efeito da interação entre terço, profundidade e meses foi significativo. Os resultados sugerem que $\boldsymbol{D}$. notus tende a se concentrar preferencialmente na parte externa da copa da planta, na face superior da folha, nos terços superior e médio. Esse comportamento ocorre principalmente nos meses de maior infestação: fevereiro, março e abril. Para os demais meses, não há uma distinção entre profundidades de copa e alturas de terços (Tabela 2).

Em estudo conduzido na cultura, em Cascavel, GAIS (2000) observou que a ocorrência de D. notus nos diferentes estratos da planta (alto, médio e baixo) foi significativamente dependente da estação do ano. No inverno e verão, os espécimes se concentravam nos estratos médio e baixo e, na primavera, apenas no estrato baixo. No outono, período de maiores infestações, localizou-se, preferencialmente, nos estratos alto e médio.

Esse último resultado assemelha-se aos alcançados no presente trabalho, provavelmente por se tratar da mesma época do ano e devido à ocorrência de altas infestações do ácaro nesse período. No entanto, difere daqueles constatados por GOUVEA (2003), ao estudar o comportamento de D. notus em plantas de erva-mate no município de Dois Vizinhos,

Tabela 1 - Resumo da análise de variância conjunta do experimento bifatorial no delineamento em blocos ao acaso com amostragem na parcela, para o número de ácaros Dichopelmus notus por $\mathrm{cm}^{2}$ de folha em plantios comerciais de erva-mate em Chapecó, SC. Santa Maria, RS, 2006.

\begin{tabular}{|c|c|c|c|}
\hline Fontes de variação & $\mathrm{GL}^{1}$ & QM & F \\
\hline Bloco:(mês) & 348 & 132,21 & $1,32 *$ \\
\hline Mês & 11 & 9327,12 & $93,13 *$ \\
\hline Terço & 2 & 5063,87 & $50,56 *$ \\
\hline Profundidade & 1 & 3313,88 & $33,09 *$ \\
\hline Mês x terço & 22 & 372,45 & $3,72 *$ \\
\hline Mês x profundidade & 11 & 1095,92 & $10,94 *$ \\
\hline Terço x profundidade & 2 & 702,00 & $7,01 *$ \\
\hline Mês x terço x profundidade & 22 & 175,82 & $1,76 *$ \\
\hline Terço x profundidade x bloco:(mês) ${ }^{2}$ & 1.740 & 100,15 & $12,36 *$ \\
\hline (Terço x profundidade x bloco x mês): folha ${ }^{3}$ & 4.320 & 8,10 & \\
\hline Total & 6.479 & & \\
\hline
\end{tabular}

${ }^{1}$ - GL = Graus de liberdade, QM = Quadrados médios e F = Teste F; ${ }^{2}$ - Erro experimental; ${ }^{3}$ - Erro amostral;

* - Significativo em 5\% de probabilidade de erro. 
Tabela 2 - Médias de Dichopelmus notus por $\mathrm{cm}^{2}$ de folha nos terços de alturas de plantas e nas profundidades da copa em cada mês do ano em plantios comerciais de erva-mate em Chapecó, SC. Santa Maria, RS, $2006{ }^{1}$.

\begin{tabular}{|c|c|c|c|c|c|c|c|c|}
\hline \multicolumn{9}{|c|}{ Mês } \\
\hline \multirow[b]{2}{*}{ Terçolprofundidade } & \multicolumn{2}{|c|}{ janeiro } & \multicolumn{2}{|c|}{ fevereiro } & \multicolumn{2}{|c|}{ março } & \multicolumn{2}{|c|}{ abril } \\
\hline & Externa & Interna & Externa & Interna & Externa & Interna & Externa & Interna \\
\hline Superior & $1,7 \mathrm{aA}$ & $1,8 \mathrm{aA}$ & $13,8 \mathrm{aA}$ & $11,4 \mathrm{aA}$ & $19,5 \mathrm{bA}$ & $13,8 \mathrm{aB}$ & $7,4 \mathrm{aA}$ & $9,0 \mathrm{aA}$ \\
\hline Médio & $1,5 \mathrm{aA}$ & $1,2 \mathrm{aA}$ & 12,3abA & $6,3 \mathrm{bB}$ & $27,4 \mathrm{aA}$ & 9,9abB & $5,9 a A$ & 2,9bA \\
\hline \multirow[t]{2}{*}{ Inferior } & $1,1 \mathrm{aA}$ & $0,5 \mathrm{aA}$ & $5,6 \mathrm{bA}$ & $3,9 \mathrm{bA}$ & $14,5 \mathrm{cA}$ & $8,0 \mathrm{bB}$ & $3,1 \mathrm{bA}$ & $3,0 \mathrm{bA}$ \\
\hline & \multicolumn{2}{|c|}{ maio } & \multicolumn{2}{|c|}{ junho } & \multicolumn{2}{|c|}{ julho } & \multicolumn{2}{|c|}{ Agosto } \\
\hline Terço\profundidade & Externa & Interna & Externa & Interna & Externa & Interna & Externa & Interna \\
\hline Superior & $3,4 \mathrm{aA}$ & $3,3 a A$ & $2,9 a A$ & $3,2 \mathrm{aA}$ & $3,8 \mathrm{aA}$ & $4,2 \mathrm{aA}$ & $6,8 \mathrm{aA}$ & $6,2 \mathrm{aA}$ \\
\hline Médio & $2,8 \mathrm{aA}$ & $1,6 a A$ & $2,3 a A$ & $1,6 \mathrm{aA}$ & $3,5 a A$ & $2,8 \mathrm{aA}$ & $6,1 \mathrm{aA}$ & $3,5 \mathrm{aA}$ \\
\hline \multirow[t]{2}{*}{ Inferior } & $1,8 \mathrm{aA}$ & $1,7 \mathrm{aA}$ & $1,5 \mathrm{aA}$ & $1,2 \mathrm{aA}$ & $2,9 a A$ & $2,1 \mathrm{aA}$ & $3,0 \mathrm{aA}$ & $2,0 \mathrm{aA}$ \\
\hline & \multicolumn{2}{|c|}{ setembro } & \multicolumn{2}{|c|}{ outubro } & \multicolumn{2}{|c|}{ novembro } & \multicolumn{2}{|c|}{ dezembro } \\
\hline Terçolprofundidade & Externa & Interna & Externa & Interna & Externa & Interna & Externa & Interna \\
\hline Superior & $5,6 \mathrm{aA}$ & $7,6 \mathrm{aA}$ & 2,3aA & $1,3 a A$ & $1,2 \mathrm{aA}$ & $1,0 \mathrm{aA}$ & $3,5 \mathrm{aA}$ & $2,8 \mathrm{aA}$ \\
\hline Médio & 4,9aA & $4,5 \mathrm{aA}$ & $2,0 \mathrm{aA}$ & $0,9 \mathrm{aA}$ & $0,9 \mathrm{aA}$ & $1,2 \mathrm{aA}$ & $2,4 \mathrm{aA}$ & $2,8 \mathrm{aA}$ \\
\hline Inferior & $2,1 \mathrm{aA}$ & 1,6bA & $0,94 \mathrm{aA}$ & $0,9 \mathrm{aA}$ & $0,8 \mathrm{aA}$ & $0,6 \mathrm{aA}$ & 1,3aA & $1,0 \mathrm{aA}$ \\
\hline
\end{tabular}

${ }^{1}$ - Médias seguidas da mesma letra minúscula na vertical e da mesma letra maiúscula na horizontal são estatisticamente iguais pelo teste de Tukey a 5\% de probabilidade de erro.

registrando a ocorrência de $\boldsymbol{D}$. notus em maior número nos estratos inferior e médio e nas folhas da região interna da copa.

Resultado parecido foi encontrado por FERLA et al. (2000), ao estudarem a distribuição espacial de Calacarus heveae Feres (Eriophyidae) em plantas de seringueira, constatando que tanto a proporção de folhas infestadas como o número do eriofídio foi maior no estrato médio.

Os resultados apresentados na literatura coincidem apenas parcialmente com os obtidos no presente estudo. As possíveis diferenças entre esses resultados podem estar associadas, além de às condições climáticas e às características fenológicas das plantas (ALVES et al., 2000), à exigência de metodologias diferenciadas para a realização dos estudos em conformidade com os objetivos a serem atingidos. Esses aspectos evidenciam a necessidade de estudos direcionados a cada região onde se verifica a ocorrência do ácaro, potencialmente danoso para a cultura da erva-mate.

Devido ao comportamento apresentado pelo ácaro na planta e à grande variabilidade nos níveis de infestação entre os meses do ano, é possível inferir que uma boa recomendação para realizar levantamentos dos níveis de infestação desse acarino na região do estudo consiste em realizar inspeções, nos meses de fevereiro a abril, na parte externa da copa dos terços médio e superior. No entanto, em plantas de porte elevado, as observações podem ser realizadas apenas no terço médio, devido ao fato de não haver diferença entre os terços médio e superior. Esse procedimento pode agilizar o trabalho de monitoramento dos níveis de infestação dessa espécie. Desta forma, pode-se amostrar três folhas por planta, em 30 plantas, selecionadas ao acaso, em talhões de um hectare (VIEIRA NETO, 2006).

Associado a essas considerações, é preciso observar as recomendações de FERNANDES at al. (2003) e de PEREIRA et al. (2004), para os quais a aplicação de planos de amostragem deve estar atrelada ao nível de ataque da praga à cultura e aos prejuízos proporcionados. Além disso, as inspeções devem ser realizadas em talhões uniformes na lavoura quanto à época de semeadura (plantio), à cultivar, à topografia, aos tratos culturais, à proximidade de possíveis focos de infestação, entre outros fatores.

Quanto ao manejo integrado de D. notus, embora a legislação brasileira não tenha nenhum produto fitossanitário registrado para o seu controle, existem algumas medidas que podem ser adotadas visando à prevenção e/ou à redução de seu nível populacional. Como práticas preventivas, pode-se utilizar barreiras vegetais do tipo quebra-vento. Essa medida dificulta a entrada e a dispersão do ácaro nos ervais, que se deslocam principalmente pela ação do vento. O uso de cobertura de solo, entre os ervais, também é recomendado, principalmente com leguminosas perenes de porte baixo. Sua floração fornece alimentos aos ácaros predadores, pertencentes aos gêneros Euseius, Iphiseiodes e Agistemus, nos períodos em que o ácaro-do-bronzeado está em baixa 
infestação, viabilizando a manutenção do seu controle biológico quando as condições climáticas o favorecem. Caso seja necessária uma intervenção com produtos químicos, recomenda-se a utilização de produtos formulados à base de enxofre, devido a sua menor toxidez em relação aos demais acaricidas e por terem períodos de carências mais curtos (CHIARADIA, 2001a).

Os valores dos coeficientes de correlação linear simples entre os elementos climáticos e o número médio de $\boldsymbol{D}$. notus por $\mathrm{cm}^{2}$ de folha oscilaram entre $r=-0,39$, a r=0,39, não apresentando significância estatística, pelo Teste “t”, em nível de 5\% de probabilidade de erro, para os diferentes locais de plantas.

Existe uma tendência de incremento da população de $\boldsymbol{D}$. notus em temperaturas mais elevadas, tanto para temperaturas mínimas $(\mathrm{r}=0,21)$ quanto para temperaturas máximas ( $\mathrm{r}=0,33)$, tendo esta última uma maior influência sobre o comportamento do acarino em todos os locais de plantas. De maneira inversa, o mesmo acontece para a umidade relativa do ar $(\mathrm{r}=-0,34)$, para a precipitação pluviométrica $(\mathrm{r}=-0,33)$ e a velocidade do vento $(r=-0,23)$, esses fatores tendem a favorecer a ocorrência do ácaro quando se manifestam em baixa intensidade.

A ocorrência de associação nãosignificativa entre os níveis populacionais de $\boldsymbol{D}$. notus, tanto para a temperatura, quanto para a precipitação pluviométrica em erva-mate, também foi constatada por GOUVEA (2003). Porém, este verificou que o vento e a umidade são fatores que interferem expressivamente na população do ácaro. Segundo o autor, o aumento da população é favorecido quando ocorrem épocas de umidade relativa mais baixa e maior velocidade de vento. A dispersão pelo vento minimizaria o efeito negativo da umidade no microclima formado no interior da copa.

Correlação negativa entre precipitação pluviométrica e ocorrência de Phyllocoptruta oleivora (Ashmead) (Eriophyidae) foi encontrada por RIBEIRO (1988) e CHIARADIA (2001b) em pomares de citros em Jaboticabal, Estado de São Paulo, e no Oeste catarinense, respectivamente. CHIARADIA (2001b) registrou, ainda, correspondência positiva significativa do eriofídio com a temperatura média mensal. No entanto, a umidade relativa do ar e o vento não interferiram na flutuação do mesmo.

Os estudos da diversidade e da flutuação populacional de ácaros em Mabea fistulifera (Mart.) (Euphorbiaceae) em fragmentos de mata estacional semidecídua em São José do Rio Preto-SP, desenvolvidos por DAUD \& FERES (2005), apontaram para uma ausência de correlação entre a pluviosidade e a acarofauna total. Segundo os autores, outros fatores, além da precipitação, podem estar mais diretamente associados à ocorrência dos acarinos. Os fitófagos, principalmente os eriofídeos, seriam beneficiados pelas condições de estresse a que as plantas estão sujeitas, pois as plantas submetidas a estresse e poluição atmosférica, por exemplo, aumentam a disponibilidade de nitrogênio em suas folhas. Esse fenômeno pode estar associado ao aumento da sobrevivência e da taxa intrínseca de crescimento populacional desses acarinos.

A dificuldade em estabelecer uma correspondência consistente entre os elementos climáticos e o número de ácaros pode estar relacionada ao fato de os níveis populacionais de pragas agrícolas, em geral, resultarem da ação e da interação de outros fatores climáticos além dos estudados aqui, como: horas de insolação, grau de nebulosidade, quantidade de evaporação, entre outros. Além disso, as próprias variáveis climáticas estão sob a influência indireta de fatores determinantes de suas manifestações, tais como: latitude, longitude, altitude, relevo, continentalidade, entre outros. Associados a essa dinâmica, estão outros fenômenos naturais, como, a presença ou ausência de predadores, a exposição e constituição do solo e a própria natureza da cultura agrícola e da espécie-praga em estudo.

\section{CONCLUSÕES}

Dichopelmus notus tende a se concentrar na parte externa da copa da planta nos terços superior e médio. As maiores infestações de $\boldsymbol{D}$. notus ocorrem nos meses de fevereiro a abril, não tendo sido encontrada correlação linear significativa entre os elementos climáticos e o número médio de ácaro por $\mathrm{cm}^{2}$ de folha.

\section{REFERÊNCIAS}

ALVES, L.F.A. et al. Ácaros fitófagos da erva-mate: situação atual e perspectivas de controle. In: CONGRESSO SULAMERICANO DE ERVA-MATE, 2., 2000, Encantado. Anais... Porto Alegre: UFRGS, 2000. p.39-42.

ANUÁRIO BRASILEIRO DA ERVA-MATE 2000. Santa Cruz do Sul: Gaseta Grupo de Comunicações, 2000. 80p.

CHIARADIA, L.A. Alternativas para o manejo do ácaro-dobronzeado da erva-mate. Agropecuária Catarinense, Florianópolis, v.14, n.2, p.5-7, 2001a.

CHIARADIA, L.A. Flutuação populacional do ácaro da falsaferrugem Phyllocoptruta oleivora (Ashmead, 1879) (Acari, Eriophyidae) em pomares de citros da região do oeste 
catarinense. Pesquisa Agropecuária Gaúcha, Porto Alegre, v.7, n.1, p.111-120, 2001b.

CHIARADIA, L.A. et al. Caracterização, danos e manejo de ácaros em erva-mate. Agropecuária Catarinense, Florianópolis, v.19, p.50-52, 2006.

DA CROCE, D.M. Cadeias produtivas do Estado de Santa Catarina: erva-mate. Florianópolis: Epagri, 2000. 31p. (Boletim Técnico, 112).

DA CROCE, D.M.; FLOSS, P. A cultura da erva-mate no Estado de Santa Catarina. Florianópolis: Epagri, 1999. 81p. (Boletim técnico, 100).

DAUD, R.D.; FERES, R.J.F. Diversidade e flutuação populacional de ácaros (Acari) em Mabea fistulifera Mart. (Euphorbiaceae) de dois fragmentos de mata estacional semidecídua em São José do Rio Preto, SP. Neotropical Entomology, Londrina, v.34, n.2, p.191-201, 2005.

DE COLL, O. de R.; CACERES, M.S. Determinación de la Fluctuación populacional del "Ácaro del bronzeado" de la yerba mate. Dichopelmus notus Keifer (Acari, Eriophyidae) y sus enemigos naturales. In: WINGE, H. et al. Erva-mate: biologia e cultura no Cone Sul. Porto Alegre: UFRGS, 1995. p.121128.

EMBRAPA. Centro Nacional de Pesquisa Tecnológica em Informática para a Agricultura. Ambiente de software NTIA, versão 4.2.2: manual do usuário - ferramental estatístico. Campinas: EMBRAPA/CNPTIA, 1997. 258p.

FERLA, N.J. et al. Spacial and temporal distribution of Calacarus heveae on rubber trees in Brazil. In INTERNATIONAL CONGRESS OF ENTOMOLOGY, 21. 1998, Rio de Janeiro. Resumos... Foz do Iguaçu: SEB, 2000. p.8.

FERLA, N.J. et al. Acarofauna (Acari) de erva-mate (Ilex paraguariensis St. Hil.: Aqüifoliaceae) no estado do Rio Grande do Sul. Biociências, Porto Alegre, v.13, n.2, p.133-142, 2005.

FERNANDES, M.G. et al. Amostragem seqüencial de Alabama argillacea (Hübner) (Lepidoptera: Noctuidae) em algodoeiro. Neotropical Entomology, Londrina, v.32, n.1, p.117-122, 2003.

GAIS, N.L. Estudo da dinâmica populacional de ácaros fitófagos na cultura de erva-mate em Cascavel PR. 2000. 33f. Monografia (Bacharelado em Ciências Biológicas) - Curso de Graduação em Ciências Biológicas, Universidade Estadual do Oeste do Paraná.

GOUVEA, A. Dinâmica populacional da acarofauna em agroecossistema ervateiro, no município de Dois Vizinhos. PR. 2003. 71f. Dissertação (Mestrado em Agronomia) - Programa de Pós-graduação em Agronomia, Universidade Estadual do Oeste do Paraná.
IBGE. Banco de Dados, 2006. Acesso em: 13 jan. 2006. Online. Disponíveis em: <http://www.sidra.ibge.gov.br/bda/ tabela>

LAVOURA PECUÁRIA. Gauchismo: história da erva-mate. Lavoura Pecuária, Rio Grande do Sul, n.5, p.46-47, 1978.

NAVIA, D.; FLECHTMANN, C.H.W. A new eriophyoid mite in the genus Disella from Ilex paraguariensis in Brazil. Zootaxa, v.1037, p.23-28, 2005.

OLIVEIRA, C.A.L. de. et al. Comparação de métodos para estimativa da população do ácaro Phyllocoptruta oleivora (Ashmead, 1879) na cultura dos citrus. Anais da Sociedade Entomológica do Brasil, Jaboticabal, v.11, n.1, p.101-114, 1982.

PASINATO, R. Aspectos etnoentomológicos, socioeconômicos e ecológicos relacionados à cultura da erva-mate (Ilex paraguariensis) no município de Salto do Lontra, Paraná, Brasil. 2003. 112f. Dissertação (Mestrado em Ecologia de Agroecossistemas) - Curso de Pós-graduação em Ecologia de Agroecossistemas, Escola Superior de Agricultura "Luiz de Queiroz”.

PENTEADO, S. do R.C. Principais pragas da erva-mate e medidas para o seu controle. In: WINGE, H. et al. Erva-mate: biologia e cultura no Cone Sul. Porto Alegre: UFRGS, 1995. p.109-120.

PEREIRA, M.F.A. et al. Amostragem seqüencial (presençaausência) para Bemisia tabaci (Genn.) biótipo B (Hemiptera: Aleyrodidae) em feijoeiro (Phaseolus vulgaris L.). Neotropical Entomology, Londrina, v.33, n.4, p.499-504, 2004.

RIBEIRO, L.G. Plano de amostragem de presençaausência e ciclo de vida de Panonychus ulmi (Koch, 1836) (Acari:Tetranychidae) em macieira Malus domestica Bork 1803. 1988. 125f. Dissertação (Mestrado em Ciências Biológicas) - Curso de Pós-graduação em Ciências Biológicas, Universidade Federal do Paraná.

SANTA CATARINA. Secretaria do Estado da Agricultura e Abastecimento. Manual de uso, manejo e conservação do solo e da água: projeto de recuperação, conservação e manejo dos recursos naturais em microbacias hidrográficas. Florianópolis, 1994. 384p.

SANTANA, D.L. de. Q. et al. Principias características de três espécies de ácaros em erva-mate, no sul do Brasil. Perspectiva, Erechim, v.24, n.88, p.135-137, 2000.

VIEIRA NETO, J. Amostragem do ácaro-do-bronzeado Dichopelmus notus Keifer (Acari, Eriophydae) na cultura da erva-mate em Chapecó, Santa Catarina. 2006. 67f. Tese (Doutorado em Agronomia) - Programa de Pós-graduação em Agronomia, Universidade Federal de Santa Maria. 